Literatura y Lingüística $\mathrm{N}^{\circ} 26$

ISSN 0716-5811 / pp. 15-28

\title{
Estrategias del yo: construcción del sujeto autorial en los textos de cinco autobiógrafas chilenas* $^{*}$
}

\author{
Lorena Amaro Castro**
}

\section{Resumen}

Entre 1891 y 1925 tiene lugar en Chile la transición desde una cultura tradicional de élites a una moderna, de masas, en que nuevos actores comienzan a tener una participación importante, como lo es el caso de las clases medias y las mujeres. Ellas se incorporan al campo literario, manifestando en sus textos autobiográficos las tensiones relativas a su posición de integrantes de las escasas familias de élite que gobiernan al país, pero que, al interior del hogar, juegan un rol subordinado. Ello incide en su autopercepción como escritoras, papel en el que incursionan como interviniendo en un espacio ajeno. Estudiaremos los textos de cinco autoras en que hemos observado estas formas tensas de construcción autorial: Iris, Rita Salas, María Flora Yáñez, Delie Rouge y Marta Vergara.

Palabras clave: autobiografía, autorrepresentación, autoría, género, escritoras chilenas.

\section{Strategies of the self: construction of the authorial subject in the texts of five Chilean autobiographers}

\begin{abstract}
Between 1891 and 1925 a transition from a traditional and elitist culture to a modern and mass-oriented one takes place in Chile. New actors begin to play relevant roles, as for instance the middle-class segment of the population and women. The latter enter the literary field, portraying in their autobiographies the tensions related, on the one hand, to their position as members of the few elite families which rule the country, and, on the other hand, their subordinate role inside their homes. This affects their self-perception as writers, a role which they approach as an intrusion into a foreign space. These difficulties encountered by female writers to express themselves will be analyzed in the texts of Iris, Rita Salas, María Flora Yáñez, Delie Rouge and Marta Vergara.
\end{abstract}

Key words: autobiography, self-representation, authorship, gender, female Chilean writers.

Recibido: 15-01-2012 Aceptado: 27-06-2012

\footnotetext{
Este artículo tiene su origen en el proyecto "Textos autobiográficos en el campo literario chileno (1891-1925): Construcciones identitarias y voces alternas", financiado primero por la Vicerrectoría Académica de Investigación y Doctorado de la P. Universidad Católica de Chile, a través de sus concursos VRAID Inicio y VRAID Límite (2007 - 2008) y luego por FONDECYT Iniciación 2008, nº Proyecto 11080008.

** Doctora en Filosofía (Universidad Complutense de Madrid). Instituto de Estética, Pontificia Universidad Católica de Chile, Chile lamaro@uc.cl
} 
Estrategias del yo: construcción del sujeto autorial en los textos de cinco autobiógrafas chilenas / Lorena Amaro Castro

El rescate de la memoria autobiográfica en Chile obliga a repensar diversas cuestiones, vinculadas tanto a la construcción del campo literario en nuestro país (por ejemplo el trazado, vigente hasta hace poco, de linajes canónicos que excluían a las escrituras referenciales), como a la significación de una escritura que trasciende la representación del pasado individual. En los textos autobiográficos, los autores plasman recuerdos, rasgos que dicen relación con inscripciones de género, clase, etnia, en una telaraña que está cosida por los cuatro costados a la realidad y a la historia nacional. Las memorias y autobiografías ofrecen, además, un interesante mirador hacia las elaboraciones del constructo identitario nacional en el último siglo; como representaciones literarias inciden, asimismo, en la generación, divulgación y reproducción de planteamientos ideológicos, en un diálogo inacabable entre textos y contextos de producción y recepción. En este sentido, el siguiente artículo pone su atención en un espectro de voces que participan de ese diálogo en un momento de grandes cambios culturales y sociales, las voces de las escritoras chilenas de la primera mitad del siglo XX, en particular cinco de ellas: Inés Echeverría (1868-1949, conocida también por su seudónimo, Iris), María Flora Yáñez (nacida en 1889, 1898 o 1901, hay discrepancias sobre la fecha - 1982), Rita Salas (1882 - 1965, su seudónimo fue Violeta Quevedo), Delia Rojas (1883 - 1950, quien firmaba Delie Rouge) y Marta Vergara (1898 - 1995).

Hay una reflexión de la crítica venezolana Márgara Russotto, que grafica bastante bien lo que ocurre con la escritura de estas autoras: "la operación memorialista tiene muchos rostros y un andar paradójico. Como los cangrejos: por un lado retrocede y por el otro avanza. $\mathrm{O}$ avanza retrocediendo. Y por este carácter bifronte, ella hace y deshace sin cesar el perfil de cada experiencia, de cada identidad, tanto colectiva como individual" (Russotto 2002: 76). Estudiar estos textos implica no sólo escudriñar la construcción íntima del yo en un período determinado, sino también, como propone esta autora, asomarse a través de sus textos a lo colectivo. Por otra parte, la literatura autobiográfica femenina, tanto en el orden personal como en lo que refiere al ámbito social, suele dar cuenta de procesos constructivos más que de productos acabados; los textos constituyen traducciones - a veces inesperadas- de las formas en que se van tramando las subjetividades, construcción en que vemos además cómo se traslapan otras cuestiones, de clase y de etnia, tan determinantes en los planteamientos discursivos latinoamericanos.

Así ocurre en el corpus propuesto: "Razón del diario. Niñez primera", en Memorias de Iris, de Inés Echeverría, publicado el 2005, pero de data

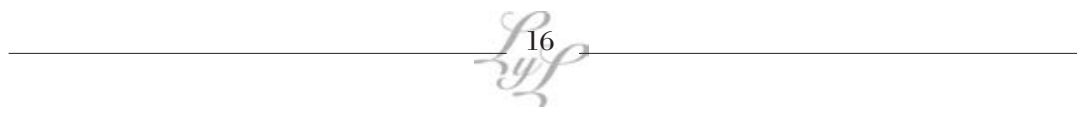


anterior (posiblemente 1934); Mis memorias de escritora, de Delie Rouge (1943); Visiones de infancia, de María Flora Yáñez (1947); Antenas del destino, de Violeta Quevedo, llamada realmente Rita Salas (1951, reúne textos de distinta data) y Memorias de una mujer irreverente, de Marta Vergara (1963). Todas ellas vivieron el período entre 1891 y 1925, de profundos cambios sociales, apuntados por autores como Grínor Rojo, Bernardo Subercaseaux y otros; en el ámbito literario, se trata de un período importante en la medida que, como señala Gonzalo Catalán (1985), en esos años se produjo un desplazamiento del campo literario, desde la llamada "constelación de las élites" — marcada por cierta indiferenciación de lo político y lo literario y un predominio absoluto del grupo oligárquico en la construcción de los discursos- a un nuevo orden literario, de carácter moderno, donde comienzan a diferenciarse los ámbitos político y cultural y, al interior de éste, diversos géneros de producción, como es el caso, a mi modo de ver, de la escritura autobiográfica y memorialística. El creciente número de alfabetizados y de medios de prensa asequibles a un público cada vez mayor, hace además necesaria la profesionalización de la escritura y también que la ciudad letrada se ponga alerta frente a estos nuevos actores: algunos, formados en la escuela pública, provincianos; otros, mujeres, de clase alta y media, hasta entonces prácticamente excluidos de la elaboración discursiva elitista.

Reviste un gran interés político y estético el que estos actores hayan introducido los cambios más relevantes en la construcción del discurso autobiográfico de la mitad del siglo en nuestro país. No solo hay un relevo de voces en el campo literario, sino que también entre quienes hilvanan los hilos del pasado a través de la escritura memoriosa: la profesionalización de la escritura permite el emerger de autobiógrafos que, a diferencia de los escritores varones de élite, encontrarán otras razones para narrar sus vidas. Muchos de ellos harán de sus historias ejemplos de mérito y esfuerzo, de sensibilidad y talento personales; otros interpelarán con ellas a sus grupos de pertenencia, ya sea migrantes, obreros o mujeres; también, en varios casos, procurarán a través de narraciones de carácter autorreflexivo, autorizar la intromisión de sus voces en la cultura escrita de este país, construyendo autorías cimentadas en la lectura. Me refiero a autores como Lautaro García, Manuel Rojas, Benedicto Chuaqui, Óscar Castro, Mariano Latorre, Carlos Sepúlveda, pero también, muy especialmente, a autoras como Iris, Delia Rojas o María Flora Yáñez.

En el caso de ellas, su lucha es particularmente ardua. Cito a la periodista Marta Vergara, quien en los años 20 observaba que las mujeres, 
Estrategias del yo: construcción del sujeto autorial en los textos de cinco autobiógrafas chilenas / Lorena Amaro Castro

lejos de ser consideradas intelectualmente, "eran puestas en altares o en floreros" (16), lo que revela la precariedad de sus posicionamientos, aun cuando fuera aquel un período de efervescencia en lo referente a la asociatividad femenina (cfr. Vicuña, 2001).

Las dificultades enfrentadas por las mujeres en tanto creadoras e intelectuales son expuestas de modo particular en el género autobiográfico. Este ha sido habitualmente considerado un producto del giro occidental hacia una individualidad burguesa, también un género ancilar, secundario como objeto literario. Pero es precisamente esta calidad de discurso excentrado y marginal lo que lo convierte en un posible espacio de agencia para las subjetividades desplazadas. A este respecto, Joanne S. Frye destaca la posibilidad que ofrece la autobiografía de tender un puente desde su autora hacia otras mujeres, por tratarse de una comunicación que "fluye de forma más directa", y en que lo ficticio es desplazado "por lo personal, por la voz de un ser real" que apela a otras, cautivas de una misma enajenación social (cit. por Orozco 1994: 297). El género es, de este modo, una ventana hacia formas en algunos casos embrionarias y en otros más desarrolladas de crítica feminista. En este sentido, Márgara Russotto juzga que "las mujeres han emprendido estas [...] operaciones memorialistas para activar un punto de vista crítico con relación al mundo, a la misma condición femenina, y a la relación particular con los discursos literarios a través de la práctica de la escritura" (2002:77).

Los textos del corpus analizado son, por otra parte, textos sobrevivientes. Ana Traverso ha apuntado, y con razón, que, en el caso de las mujeres de clase media, cuya historia es de difícil reconstrucción para los historiadores, las autobiografías, muchas de ellas nacidas de un diario de vida, permiten asomarse a fragmentos de vida que en la mayor parte de los casos no dejaron huella. Traverso habla de diarios quemados, de experiencias que fueron reconstruidas, por pudor o delicadeza con los familiares, en otras formas escriturales: cuentos, poemas. Los textos que aquí analizaré, algunos de autoras de clase media, la mayoría de ellos de mujeres de la élite, pudieron remontar ese límite del pudor o la conveniencia pero siguen siendo escasamente divulgados y analizados. Es muy gráfico el caso del texto de Delie Rouge, al que se puede acceder apenas en la Biblioteca Nacional, en una copia cosida a otros textos diversos, misceláneos. Se trata de textos aparentemente subordinados; sus creadoras, incluso cuando ocupan un lugar de élite, se encuentran asimismo subordinadas en el plano doméstico pero también en el plano intelectual, por lo que instalan desde allí sus problemáticas, tensas narraciones, en que se representan a sí mismas en su cotidianeidad, pero

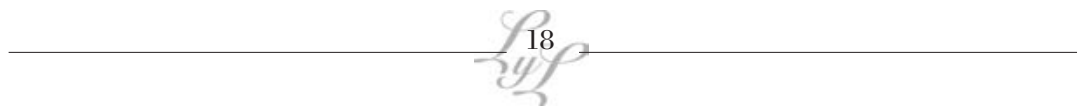


muy particularmente -y esto es lo que se analiza con más profundidad aquí- como sujetos intelectuales y creadores.

\section{Autobiografía: qué se representa}

Afirmación y retraimiento, figuración y desfiguración se encuentran tensionados en las autobiografías de mujeres que emergen en la escena literaria chilena. El crítico José Amícola acota que "la dosis de soberbia que implica escribir una autobiografía" es algo aún más complejo si se trata de la de una mujer, ya que su posición habitualmente subordinada les ha impedido a las autoras "afirmarse", del modo en que lo ha hecho el varón "como derecho propio" (Amícola 59)․․ En las autoras aquí abordadas predomina la aceptación de los papeles preestablecidos; sin embargo, también, de alguna forma se interroga o tuerce el relato hegemónico, patriarcal, planteando fisuras textuales que finalmente afirman a sus autoras en su condición de escritoras. Como plantea Russotto, a propósito de la construcción autorial femenina, "el ejercicio de la autoría se sitúa en un escenario 'íntimo', autorreferencial, y desde una otredad semioculta y poco convencional" (2006: 14), lo que hace de estos textos documentos particularmente interesantes. La "doble voz" a la que alude el discurso feminista ${ }^{2}$, les permite, como autoras, insertarse en formatos de tradición masculina, pero con un registro particular. Por eso no ha de extrañarnos que ellas puedan emplear un género utilizado en el siglo XIX como vehículo de autojustificación pública, ámbito al que sólo ellos, los varones, pueden aspirar hasta muy entrado el siglo XX en Latinoamérica, como una forma propia, válida, de expresión.

El período estudiado es, por lo demás, de una intensa producción discursiva en torno a la nación, en que la mujer funciona como símbolo, pero no como productora ni como agente política o cultural; su exclusión, cito a Lucía Guerra, "asume [... ] una firme plataforma simbólica que hace

$1 \quad \mathrm{Al}$ abordar las estrategias discursivas de la autobiografía en su relación con las cuestiones de género, Amícola se refiere al origen de estos textos, en la necesidad de presentar un Yo "personaje", escindido del Yo que enuncia en un proceso de objetivación. Ambos buscan su afirmación social y esto es posible solo, como él plantea, "a partir de una condición de posibilidad, centrada en la conciencia de la importancia de su individualidad como patrón de lectura subjetiva y moderna" (17), por lo que no es casual, dice, que los autores de autobiografías fundantes no sean sino varones convencidos de su rol en el mundo.

2 Hay críticas que se han referido a una "doble visión" del texto de la mujer, o un discurso de "doble voz", en alusión a las ideas de dialogismo y heteroglosia bajtinianas, ideas que figuran en estudios señeros del llamado "segundo feminismo", como los de Elaine Showalter (1985) o, en el caso del concepto de palimpsesto, en tanto doble historia, de Gilbert y Gubar (1979). 
Estrategias del yo: construcción del sujeto autorial en los textos de cinco autobiógrafas chilenas / Lorena Amaro Castro

de la mujer la reproductora biológica y la engendradora de la colectividad nacional, puesto que posee la función de transmisora de los valores que rigen la nación" (112), pero se le niega toda posibilidad de participación activa en la construcción de nuevos significados culturales para la región. Desde un lugar incómodo, pues, ellas intentan acomodar sus escrituras, logrando en un par de casos -principalmente los de Rouge y Vergara, escritoras que no pertenecen a la élite, pero vienen de familias con educación- la conformación de una imagen de sí mismas como escritoras. ¿Qué convicción sobre su papel podían tener las autoras que aquí serán revisadas de su papel como escritoras? ¿Muchas de ellas, autoras de un libro único donde registraron, algunas muy soslayadamente, la historia de sus vidas? Propongo abordar sus estrategias de "autorrepresentación", o, como diría Sylvia Molloy, de "autofiguración", entendiendo por ello la forma representacional que aparece en los escritos autobiográficos de un autor, "complementando, afianzando o recomponiendo la imagen propia que ese individuo ha llegado a labrarse dentro del ámbito en que su texto viene a insertarse" (Amícola, 14). En particular, aquí me detendré en su escenificación como lectoras precarias, en pasajes que revelan los esperables conflictos relativos a su autoinstrucción, en una sociedad que, hacia comienzos del siglo XX, no educaba públicamente a las mujeres y mucho menos consideraba su igualdad jurídica y política.

\section{La lectura, en "el último cuarto del largo corredor"}

La totalidad de estos textos apelan al lector, intentando justificar no la actuación pública de sus autoras (algunas de ellas confinadas a una domesticidad silenciosa), sino principalmente solicitando comprensión e incluso perdón por incursionar en terrenos que no les son propios, como la escritura. Durante el período estudiado y en la región del Cono Sur, la necesidad de una lectura indulgente aparece tanto en los textos de hombres como en aquellos escritos por mujeres ${ }^{3}$. Pero son particularmente estas últimas quienes se muestran más tímidas, por su escasa

3 Me refiero en detalle a este tema en el artículo "Que les perdonen la vida: autobiografías y memorias en el campo literario chileno". (V. Bibliografía). Varios de los autobiógrafos reunidos en el corpus de esta investigación aluden a la desconfianza o desagrado que provoca la literatura íntima en la santiaguina sociedad de "buen tono" (v. Barros y Vergara, 65), incluso muy entrado el siglo, lo cual hace particularmente valioso, como gesto, el hecho de que estas autoras escriban sus autobiografías y no otro tipo de textos que pudieran haber sido acogidos con mayor benevolencia. Cito por ejemplo a Iris: "Recorro mi diario y no encuentro casi nunca esos pequeños detalles de vida íntima, tan despreciados entonces y los únicos reveladores ahora de mi existencia secreta." (Echeverría 82).

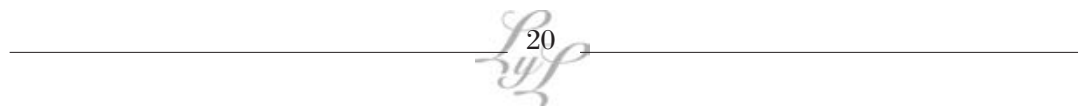


instrucción y las originales vías a través de las cuales debieron hacerse de un bagaje cultural.

Crítica literaria, periodista y novelista, Inés Echeverría Bello, "Iris", plantea una compleja construcción identitaria y autorial. En su escritura, sin lugar a dudas más autoconsciente y más polémica y radical que la de sus contemporáneas en su incipiente feminismo, explicita a través de una genealogía principalmente paterna, su condición de aristócrata pero también, por otra parte, subraya que si bien ha nacido en el seno de una familia de gran prestigio intelectual, las limitaciones que debe enfrentar como mujer perteneciente a esa élite son muchas. Así lo plantea en Memorias de Iris (texto publicado post mortem): "Nací nieta, por carencia de madre. Arraigo en la misma Colonia y nazco en el riñón de la aristocracia entre las calles Catedral, Congreso y los Tribunales de Justicia" (Echeverría 2005: 15). La primera aseveración va más allá de la inscripción biográfica: la carencia de madre la hace nieta y por tanto heredera de una tradición fundada en el patriarcado. La figura del abuelo, José Echeverría, será fundamental en su formación. Sin embargo, en su niñez y crianza, se verá sometida al régimen que corresponde a las mujeres de las familias acomodadas:

Tuve una infancia mimada, vida fácil, lujosa, abundancia de todo lo material. Clausura monjil en las costumbres. Clichés, viejos discos usados en la conversación. Carencia absoluta de intelectualidad. Religión primitiva, puro sentimiento sin luz espiritual, almas adocenadas, mediocres, pero sanas, puras, nobles y abnegadas. (Ibíd.)

Acceso a la historia, la cultura, la política, el poder, pero al mismo tiempo, negación del acceso: este es el dilema que la condujo, como ella misma refiere en sus textos, a una crisis nerviosa en su madurez. La crisis se resolvió en la producción textual, en la búsqueda de su ser como escritora. Inés Echeverría, en este como en otros pasajes, plantea sin tapujos las limitaciones con que se encontraban las mujeres de la aristocracia chilena, incluso cuando se criaban al interior de una familia intelectual como la suya, en que destaca la presencia del legislador, gramático y poeta Andrés Bello. Alfabetizadas tardíamente, herederas de prejuicios y normas estrictas, el destino de muchas de estas mujeres era, en lo doméstico, un matrimonio por conveniencia y el replegamiento en el gobierno de la casa; en lo textual, una conducta mimética y silenciosa o la incursión en géneros habitualmente relegados a un segundo plano (diarios, cartas, poesía "sentimental"), sin lograr publicar. El caso de Iris es excepcional, particularmente porque logró 
Estrategias del yo: construcción del sujeto autorial en los textos de cinco autobiógrafas chilenas / Lorena Amaro Castro

incursionar en géneros como la novela y en ámbitos de proyección pública, como el periodismo.

En cuanto a la instrucción recibida, aunque providencial, en su relato de infancia, que abarca los primeros trece años, es fundamental la presencia tutelar del abuelo, José Echeverría, con quien abre y cierra su narración: "Tatita Pepe me llevaba a su escritorio. Era el último cuarto del largo corredor. Allí me enseñaba historia sagrada y catecismo. Cuando fui más grande le leí a él los diarios, las largas correspondencias de Blanco Cuartín en la guerra del 79" (Echeverría: Ibíd.). Esta "escena de lectura" (Molloy 1996) acontece en un rincón de la casa. Si bien se trataba de textos limitados a la religión y la actualidad, fue al menos suficiente para despertar en ella las inquietudes que la llevarán a desarrollar una brillante carrera como polemista y periodista. Por otra parte, en Iris coexistirán, con el tiempo, la historia sagrada y los misterios teosóficos que fascinaron a tantos de sus coetáneos (entre ellos Rubén Darío y Gabriela Mistral). Escena de lectura suficiente, que permitió que de la "criatura frívola, insensible", naciera "la dolorosa mujer que soy" (ibíd.: 27), a la que, sin embargo, sólo el amor habría de enseñarle "el Espíritu": tal fuente amorosa fue aparentemente su marido (Joaquín Larraín Alcalde), con quien habría de viajar por Europa, periplo iniciático que casi todas estas memorias registran (la única excepción es Delie Rouge).

Por otra parte, en Iris, como en otras de las escritoras chilenas de comienzos del siglo, es usual la francofilia, al punto que no sólo toma como referentes los textos franceses, sino que además se expresa en esa lengua. Este rasgo dice relación con su instrucción, como se deja ver en una entrevista, realizada por la feminista Amanda Labarca:

De muchacha y viviendo todavía en el austero enclaustramiento de la familia, sentía ya el impulso de escribir, pero me daba cuenta también de lo inaudito de semejante impulso: juna muchacha escribiendo, y escribiendo literatura! Y no obstante y a pesar de todo yo sentía imperiosamente la necesidad de dar forma a mis pensamientos y a mis ensueños. No hubo más que un medio de conciliar mis vehementes deseos con el natural pudor de substraer mis escritos a los comentarios y a las burlas, y escribí en francés. Las voces extranjeras llegaron a hacérseme habituales y durante mi vida he redactado el diario de mis días en la lengua que yo amaba más... (Labarca, "La vida del espíritu", entrevista a Iris, Rev. Familia, 1915:3-4, cit. por Doll 2007)

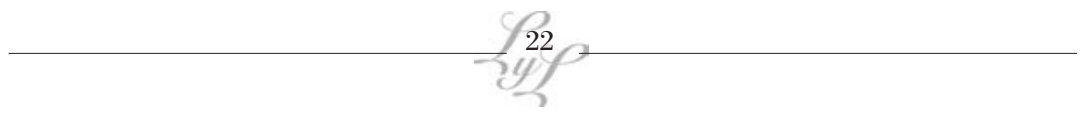


Esta necesidad de expresión incomprendida, que determinará la particular relación con el idioma materno, se observa en las distintas autoras, con variados matices. Todas ellas se construyen como sujetos intelectuales frágiles, debidos a figuras de autoridad, como un abuelo o un tío. Pero esta apertura no bastará para que asuman un papel efectivo como escritoras, ni siquiera en el caso de Iris, víctima, como otras de ellas, de enfermedades nerviosas, de "angustias inmotivadas" (Echeverría 29) e interminables búsquedas por los sanatorios y casas de reposo europeos. En todas ellas pesará el hecho de no haber contado con una instrucción suficiente para enfrentar los desafíos de la escritura.

Violeta Quevedo, en prácticamente todos sus textos, da cuenta de sus limitaciones en este sentido. Así, por ejemplo, para contar simplemente sobre un cerro que ha visto en La Serena:

No me encuentro muy capaz de describirlo, pues he sabido que ya lo han hecho personas mucho más eruditas que yo y estas impresiones son únicamente motivadas, ya por complacer a ciertos amigos y primas que deseaban conocer la descendencia de abolengos de estas tierras (...) que en cuanto está a mi alcance lo haré. (Salas op.cit.: 61)

Muy distinto es el caso de María Flora Yáñez, menor que Violeta y, a diferencia de ella, autora de varios textos, la mayoría novelísticos ${ }^{4}$. Yáñez obtuvo varios reconocimientos y se mostró socialmente como escritora en su calidad de primera presidenta del Pen Club chileno. Con más conciencia de su actividad escritural y más ambiciones estéticas que Violeta Quevedo o Marta Vergara, escribió dos textos autobiográficos de muy distinta índole: Visiones de infancia (1947), que le valió el reconocimiento de la crítica, e Historia de mi vida, que terminó de escribir con más de 80 años y es presentado como un testamento de "una ya larga carrera literaria" (1980: 8). Este último libro integra diversos retazos: cartas, reflexiones, fragmentos de diarios. La presencia de su padre, el político Eliodoro Yáñez, en el centro del relato, hace un contrapunto con la ambigua ocultación que ella hace de sí misma en el prólogo del libro. Allí promete, por una parte, "entregar su alma sin reservas" a los lectores, tópico rousseaniano de la sinceridad. Pero, al mismo tiempo, les solicita algo curioso: "que olviden que soy yo, María Flora Yáñez, a la que muchos conocen de nombre, de vista o personalmente, la que escribe este

4 Los textos de Yáñez los he abordado con más detenimiento en el artículo "María Flora Yáñez: Itinerario de un nombre". 
Estrategias del yo: construcción del sujeto autorial en los textos de cinco autobiógrafas chilenas / Lorena Amaro Castro

libro y únicamente piensen que se trata de un ser humano que les cuenta su vida, con sus grandes pesares y también con una dosis de felicidad: sol y bruma" (Ibíd.: 7). Lo que se pretende ignorar aquí es la presencia social de una destacada mujer de la élite. Con la elisión del nombre, se remonta la pesada carga que éste, muy bien conocido, impone a una mujer atrapada por las convenciones, a la que su propio padre -figura señera en su instrucción y quizás la más gravitante en los recuerdos relativos a su infancia, en que se prefigura a la escritora- le recomienda, sostenidamente, que desista de la carrera de escritora: "Nunca me resignaría a ser sólo una buena dueña de casa. Era indispensable que se realizaran mis inquietudes artísticas. Pero ¿cómo? El impulso debía nacer de mí misma puesto que nadie me ayudaría. Mis padres menos que los demás" (ibíd.: 117). Es de ellos de quien emana, probablemente, esta dura lección, contra la cual la escritora luchó hasta bien entrados los treinta años: "...una mujer se ridiculiza si no escribe algo genial o, por lo menos, excelente; un hombre puede escribir cualquier obra insignificante. Para el sexo débil no existe término medio: o gran talento o nada. Y ¿tendré talento? Me lo pregunto a menudo" (ibíd.: 196). Es, pues, entre la tachadura del nombre y la afirmación del texto como testamento autorizado por la trayectoria literaria de la autora, que transitan el propósito y las autopercepciones de Yáñez.

Por su parte, Delie Rouge plantea las falencias de su instrucción, pero en todo el corpus es quizás la única, que desde las primeras páginas, hace un defensa de su vocación escritural:

Escribo porque nací escritora, lo tengo por herencia. Mi padre en su juventud fué un buen escritor satírico que, con su pluma fina y cáustica, moralizó un pueblo del norte de Chile de costumbres depravadas (misma tendencia: batallar con la pluma). Él con varios amigos sostuvieron, por mucho tiempo, un periódico que tenía por único fin censurar los vicios y la vida corrompida de los mandatarios. (Rouge 9)

Al padre se suman dos hermanos escritores y los primos de la autora, entre ellos una prima, de seudónimo Elena Ivens, directora de una revista. Concluye, pues, Delie Rouge: "Está en mi sangre ser escritora" (ibíd.). El camino para llegar a serlo es arduo. El padre concede pagar lecciones de castellano a un profesor del Liceo de Hombres, quien intenta hacerla dudar de sus creencias religiosas, recibidas en un colegio de monjas. Para ello, el instructor le exige temas de composición tales como "Jesucristo fue un bandido". Delie Rouge le responde con un texto titulado "La beata revoltosa". Pero más allá de estas lecciones particulares,

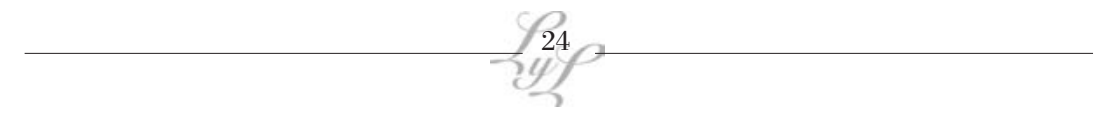


de difícil diálogo, ella se adiestra como escritora a través de la redacción de su diario, sufriendo nuevamente a causa de la mirada y los deseos masculinos que procuran doblegarla:

Escribí mi Diario de juventud lleno de inquietudes, ilusiones y desengaños hasta que conocí a tu padre -escribe Delia a su hija-. Él me pidió que no lo continuara porque en él debía depositar toda mi confianza. Pocos días después de nuestro matrimonio fué destruido. Entre rojas llamas vi desaparecer para siempre la historia de mi alegre y feliz juventud. Si debo ser sincera, hija mía, te diré que cuando vi retorcerse entre las llamas los cuadernos que encerraban mis sueños, mis ilusiones y toda mi vida de soltera, sentí un dolor inmenso. Era como algo que se iba para siempre, como algo que desgarraba en mi alma. Tu padre miraba indiferente, insensible, la destrucción de mis cuadernos. (11)

Este momento, que recuerda dramáticamente, es solo el preludio de los incontables despojamientos que relata la novelista Delie Rouge. Otro tanto debe enfrentar la irreverente Marta Vergara, quien en su texto se queja de no haber terminado los estudios. Explica que fue su intención completar el colegio comenzado con las monjas en un liceo público, pero al intentarlo se encontró con que no le convalidaban los cursos dictados en el colegio particular, por lo que debió empezar las humanidades nuevamente. Es así, pues, que se decide que su educación "quedara en lo que estaba" (9), en medio de una fuerte crisis económica familiar. Aun así, ella demuestra interés por aprender, y es significativa la escena de lectura que presenta, en que una Marta aún muy niña, junto al brasero familiar en que cocina, procura leer novelas. Caminando por las calles, cuenta, "trataba de desprenderme de esa pesada sensación de ser la causa de muchos desagrados; de poseer un cuerpo que precisaba alimentar, vestir, calzar y a veces mejorar; de ser opinadora y querer tener experiencias personales" (12). Aparece, pues, su anomalía: "Para colmo de males, me tildaban, no sé por qué, de inteligente. En el fondo era un bicho raro, triste, amargo, condenada por mansedumbre al sacrificio, que se defendía con la burla y aparentaba superioridad" (16). Aun así y siendo todavía muy joven, Marta Vergara logró ingresar al Círculo de Bellas Artes, cuya formación le pareció insuficiente, por lo que decidió hacer carrera en Europa, sin apoyo ni dinero, iniciando una vida de periodista. Su historia, como las que hemos analizado anteriormente, revela hasta qué punto, pues, la lucha por la instrucción fue ardua en Chile, más aún el reconocimiento al que podía aspirar una escritora. Todas ellas debieron seguir forzando la letra, ya fuera que lograsen crear un espacio de instrucción en la tertulia literaria, o bien 
Estrategias del yo: construcción del sujeto autorial en los textos de cinco autobiógrafas chilenas / Lorena Amaro Castro

que consiguieran tribuna e interacción intelectual en medios de prensa u organizaciones civiles. Asomarse por la rendija, divisar la oferta intelectual y política de que gozaban sus hijos o sus compañeros, productivizarla en sus propios textos, fueron estrategias que ocuparon para infiltrarse en el tramado cultural de la modernización. Legaron textos autobiográficos que debieran ser considerados algo más que fuentes históricas; son textos donde las sujetos no hegemónicas -discriminadas incluso cuando formaban parte de la clase social dominante de todo un país-construyen posiciones, voces y miradas capaces de interpelarnos, hoy, sobre el desasosiego y el desacomodo de la mujer escritora.

\section{Bibliografía}

Amaro, Lorena. "Que les perdonen la vida: Autobiografía y memorias en el campo literario chileno". En: Reviste Chilena de Literatura, 2011; (78): 5-28.

"María Flora Yáñez: Itinirario de un hombre". En: Salomone, Alicia, Lorena Amaro y Ángela Pérez (eds.). Caminos y desvios. Lecturas críticas sobre género y escritura en América Latina. Santiago de Chile: Cuarto Propio. 2010.

Amícola, José. Autobiografía como autofiguración. Estrategias discursivas del Yo y cuestiones de género. Buenos Aires: Beatriz Viterbo. 2007.

Barros, Luis y Ximena Vergara. El modo de ser aristocrático. Santiago: Aconcagua. 1983.

Catalán, Gonzalo. "Antecedentes sobre la transformación del campo literario en Chile entre 1890 y 1920". En: Brunner, José Joaquín y Gonzalo Catalán. Cinco estudios sobre cultura y sociedad. Santiago: FLACSO. 1985.

Doll, Darcie. "Desde los salones a la sala de conferencias: mujeres escritoras en el proceso de constitución del campo literario en Chile". En: Revista Chilena de Literatura, noviembre, no 71:83-100. 2007.

http://www.scielo.cl/scielo.php?pid=S071822952007000200005\&script=sci_arttext, consultado el $12 / 01 / 2012$

Echeverría Bello, Inés (Iris). Memorias de Iris. Santiago de Chile: Aguilar. 2005.

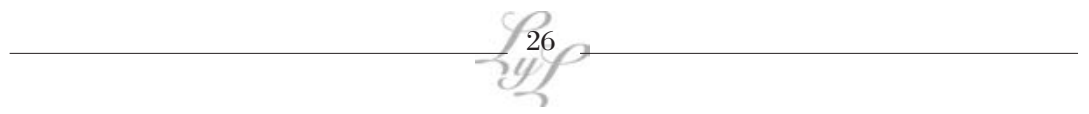


Guerra, Lucía. Mujer y escritura. Fundamentos teóricos de la crítica feminista. Santiago de Chile: Cuarto Propio. 2008.

Gilbert, Sandra y Susan Gubar. The Madwomen in the Attic. The Woman Writer and the Nineteenth-Century Literary Imagination. New Haven: Yale University Press. 2000.

Massiello, Francine. Entre civilización y barbarie. Mujeres, Nación y Cultura literaria en la Argentina moderna. Rosario: Beatriz Viterbo. 1997.

Molloy, Sylvia. "El lector con el libro en la mano". En: Molloy, Sylvia. Acto de presencia. La escritura autobiográfica en Hispanoamérica. México: FCE. 1996.

Orozco Vera, María Jesús. "La forma autobiográfica como configuración del discurso literario femenino en la narrativa de Marta Brunet, María Flora Yánez, María Luisa Bombal y María Carolina Geel". En: Anales de literatura hispanoamericana, No 23, pp. 295-314. 1994.

Rojas, Delia (Delie Rouge). Mis memorias de escritora. Santiago de Chile: Talleres Gráficos Casa Nacional del Niño. 1943.

Russotto, Márgara. "Memorialismo femenino en América Latina". En: Revista Taller de Letras 31, pp. 75 - 83. 2002.

"Presentación". En: Russotto, Márgara (compilación y edición). La ansiedad autorial. Formación de la autoría femenina en América Latina: los textos autobiográficos. Caracas: Equinoccio. 2006.

Salas Subercaseaux, Rita (Violeta Quevedo). Antenas del destino. Santiago de Chile (s/n). 1951.

Showalter, Elaine. 1985. "Feminist Criticism in the Wilderness". En: The New Feminist Criticism: Essays on Women, Literature, Theory. Elaine Showalter Ed., pp. 243 - 270, New York: Pantheon. 1985.

Traverso, Ana. "Los diarios que se quemaron". En: Revista Dossier, UDP, $\mathrm{n}^{\circ}$ 10. 2010. Recurso digital: http://www.revistadossier. cl/detalle.php?id_dos=93, consultado el 10/01/2011.

Vergara, Marta. Memorias de una mujer irreverente. Santiago: Zigzag, 1963.

Vicuña, Manuel. La belle époque chilena. Alta sociedad y mujeres de élite en el cambio de siglo. Santiago de Chile: Sudamericana, 2001. 
Estrategias del yo: construcción del sujeto autorial en los textos de cinco autobiógrafas chilenas / Lorena Amaro Castro

Yáñez, María Flora. Historia de mi vida. Fragmentos. Santiago de Chile: Nascimento. 1980.

Visiones de infancia. Santiago de Chile: Zigzag. 1947. 